\title{
The Effects of On-Going Seismic Activity on Air Quality in Canterbury, New Zealand
}

\author{
E. R. Somervell ${ }^{* 1}$ and T. Aberkane ${ }^{2}$ \\ ${ }^{I}$ The National Institute of Water and Atmospheric Research, Private Bag 99940, Auckland 1149, New Zealand \\ ${ }^{2}$ Environment Canterbury, Christchurch, New Zealand
}

\begin{abstract}
The New Zealand region of Canterbury has experienced over three years of frequent seismic activity, centred under or near the main city of Christchurch. Larger earthquakes and aftershocks have triggered liquefaction in certain parts of the city, depositing significant amounts of fine silt on the surface, which is a new source of dust emissions.

Historically, concerns about air quality in Christchurch have been dominated by emissions from wood burning in winter for domestic heating. High emissions, along with frequent temperature inversions lead to regular exceedances of the national standard for $\mathrm{PM}_{10}$ of $50 \mu \mathrm{g} \mathrm{m}^{-3}$ for a twenty-four hour average concentration. The health effects of $\mathrm{PM}_{10}$ are widely acknowledged, and regulatory drives to improve ambient air quality are succeeding in recent years.

During 2011, ratios of $\mathrm{PM}_{2.5}$ to $\mathrm{PM}_{10}$ suggested that some periods of elevated concentrations were due to the liquefaction from the earthquakes and that the silt may represent a novel air quality issue to be managed.

In addition, the earthquakes have damaged thousands of residences, causing changes in domestic heating practices as many chimneys are destroyed or currently in need of repair. This will affect emissions in upcoming winters and thus, the health burden may alter if a permanent step change in wood burning emissions is observed. However, the increased dust levels from liquefaction introduce a potentially compounding factor to any estimates of exposure.

Thus, as a result of the earthquakes, air quality in Christchurch is rapidly changing with unknown effects on exposure and ultimately, the health of the Christchurch population.
\end{abstract}

Keywords: Air pollution, earthquakes, New Zealand.

\section{INTRODUCTION}

The city of Christchurch on New Zealand's South Island has experienced over three years of regular seismic activity, beginning unexpectedly with an earthquake of magnitude 7.1 on September $4^{\text {th }} 2010$, just east of the city. Between then and the end of 2012, there were over 10,000 aftershocks, including three more quakes over magnitude 6.0. The most devastating of these occurred on February $22^{\text {nd }}$ 2011, which killed 185 people and destroyed a large proportion of Christchurch's central business district. Throughout the city over 70,000 residences and commercial buildings were damaged.

The purpose of this letter is to inform about the initial air quality effects observed in Christchurch related to the continuing seismic activity, and to reflect upon the possible future changes in air quality due to the earthquakes.

\section{Liquefaction}

A consequence of Christchurch's sitting on an alluvial plain is that areas of the city, particularly the eastern suburbs, are built on sandy soils that lose cohesion during earthquakes through a process called liquefaction. During liquefaction,

*Address correspondence to this author at the National Institute of Water and Atmospheric Research, Private Bag 99940, Auckland 1149, New Zealand; Tel: +64 9 3752038; E-mail: elizabeth.somervell@niwa.co.nz large deposits of fine silt are brought to the surface. So far, over 500000 tonnes have been cleared from the city [1], but residues remain in places hard to reach with heavy machinery and in areas that have been categorized as unfit for reconstruction by the government. Fig. (1) shows the location of Christchurch; and Fig. (2) shows areas of substantial liquefaction damage in the city after the February 22 quake.

\section{Relationships Between Urban Air Quality and Seismic Activity}

There is little documentation on the effects of earthquakes on air quality, although there are interesting investigations into using changing levels of air pollutants as an indicator for imminent seismic activity in Greece [3] and Taiwan [4]. From the little published research, air quality effects from earthquakes are attributed to the dust generated by the destruction of buildings [5]. Undoubtedly, there was enormous dust generated during the February 22 earthquake, as documented by Gilly Needham in Fig. (3); however power to the St. Albans air quality measurement site (Fig. 2) was knocked out by the quake and was not restored for three days, meaning that no measurement data are available for Christchurch for that period. 


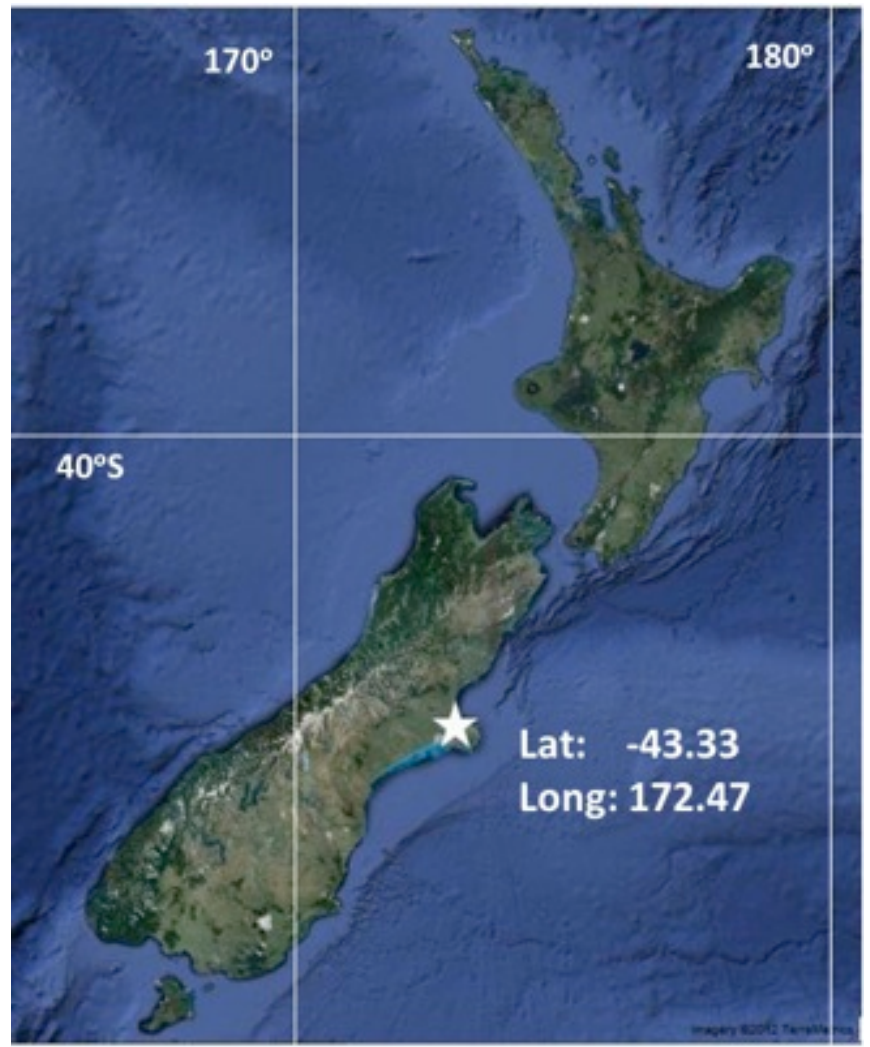

Fig. (1). Location of Christchurch (white star) on the eastern coast of the central South Island of New Zealand. Map produced with Googlemaps.
Other urban areas have experienced liquefaction during earthquakes, particularly in Greece [6] and Turkey [7], and although work has been published on the dangers liquefaction poses to buildings and industry, its potential contribution to local air quality is unknown. Estimating dust entrainment from any source is difficult, but particularly so when the source is of an unknown size and broadly distributed.

\section{AIR QUALITY IN CHRISTCHURCH}

\section{Contributing Meteorological Conditions}

Christchurch is located on the eastern edge of the Canterbury plain approximately $100 \mathrm{~km}$ from the foothills of the Southern Alps, which produce a regional katabatic wind flow across the entire plain. More locally, the Port Hills bounding the southern edge of the city rise up 400m and are also a source of cold air drainage flows [8]. Both these features contribute to frequent stable inversion layers over the city during winter, which contribute to elevated $\mathrm{PM}_{10}$ concentrations.

\section{Elevated $\mathrm{PM}_{10}$ Concentrations in Christchurch Prior to September 2010}

Christchurch experiences relatively good air quality except during the winter, when emissions from domestic wood-burning and frequent temperature inversions combine to cause exceedances of the National Environmental Standard for air quality (NESAQ), which for $\mathrm{PM}_{10}$ is a 24 hour mean concentration of $50 \mu \mathrm{g} \mathrm{m}^{-3}$. It is estimated that $70 \%$ of all $\mathrm{PM}_{10}$ in Christchurch is from domestic heating [9]. As noted in other studies [10,11], most emissions from

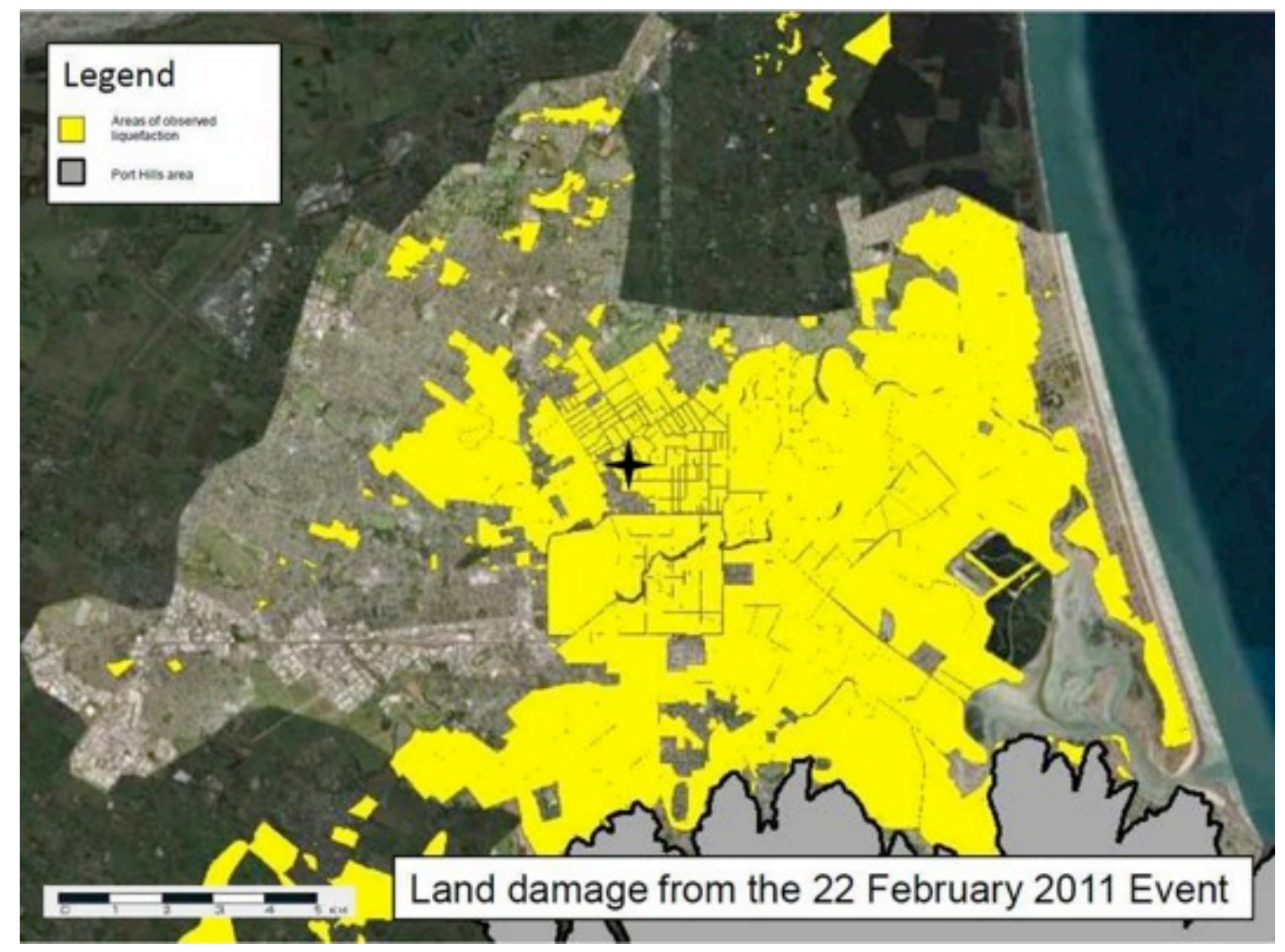

Fig. (2). Map of observed liquefaction damage in Christchurch, produced by CERA, the Canterbury Earthquake Recovery Authority [2]. Black star is the location of the St. Albans air quality monitoring site. 


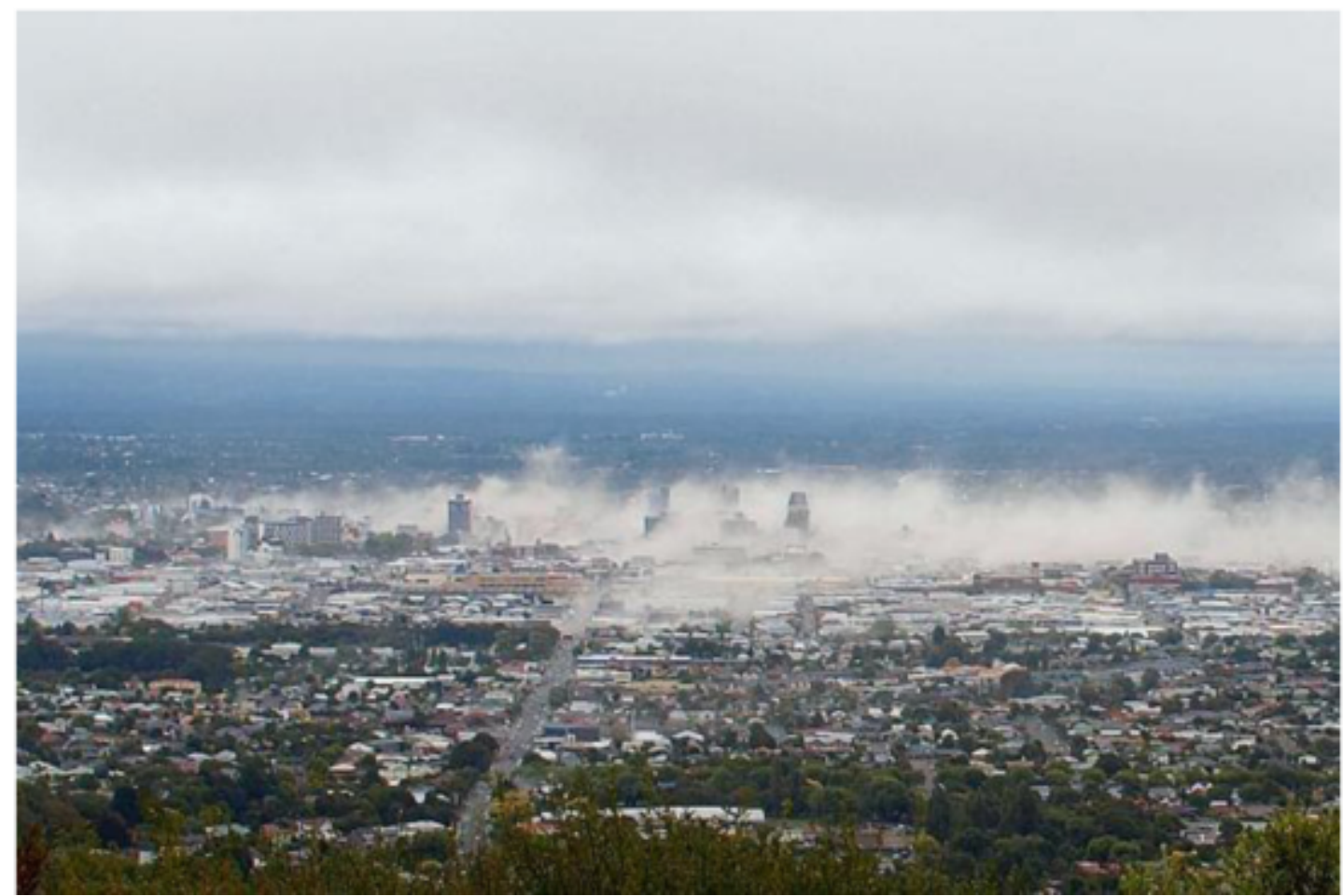

Fig. (3). Photo taken from the Port Hills looking north towards the city centre, 12 minutes after the February 22 earthquake. Taken by Gilly Needham.

wood burning fall within the $\mathrm{PM}_{2.5}$ fraction. There is no standard for $\mathrm{PM}_{2.5}$, however Environment Canterbury, responsible for monitoring air quality in Christchurch, has measured $\mathrm{PM}_{2.5}$ at its primary Christchurch monitoring site in the suburb of St. Albans since December 2010. Fig. (2) shows the location of the St. Albans site within Christchurch. The following analysis of particulate matter concentrations is undertaken using the hourly and 24-hourly averaged data from this primary air quality monitoring site, using data recorded by a Tapered Element Oscillating Microbalance with Filter Dynamics Measurement System (TEOM FDMS).

\section{Observed Ratio of Particulate Matter During Elevated Concentrations}

$\mathrm{PM}_{2.5}$ has been measured intermittently by Environment Canterbury and, where data are available, a consistent relationship between $\mathrm{PM}_{10}$ and $\mathrm{PM}_{2.5}$ has been observed during wintertime periods of elevated $\mathrm{PM}_{10}$ concentrations, shown in Fig. (4). For such periods, when the source of air pollution is domestic wood-burning, $\mathrm{PM}_{2.5}$ concentrations are at least 0.8 of $\mathrm{PM}_{10}$ concentrations. This has also been noted in the research of [12]. Fig. (4) shows the relationship derived from the historic data between $\mathrm{PM}_{10}$ and $\mathrm{PM}_{2.5}$ measurements, with around $90 \% \mathrm{PM}_{2.5}$ per $\mathrm{PM}_{10}$ (regression equation in Fig. 4).

\section{AIR QUALITY SINCE THE EARTHQUAKES}

\section{Observed Ratio of Particulate Matter Post Liquefaction Events}

Environment Canterbury recommenced $\mathrm{PM}_{2.5}$ measurements at St. Albans in late 2010 after the September 2010 earthquake, to investigate whether $\mathrm{PM}_{10}$ concentrations were

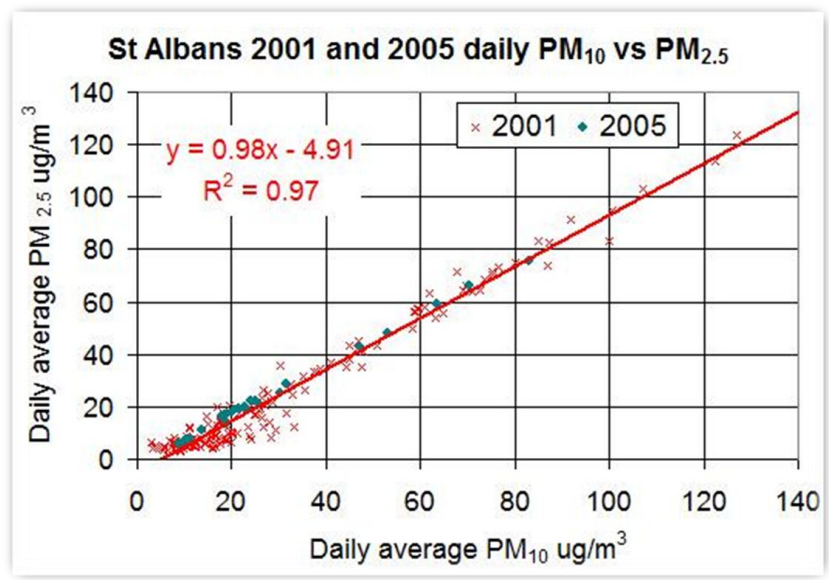

Fig. (4). Historical $\mathrm{PM}_{2.5}$ and $\mathrm{PM}_{10}$ data from St. Albans monitoring site, indicating a consistent relationship during elevated concentrations [13].

being influenced by increased particulate matter in the coarse 2.5 to 10 micrometre size range. Since then, periods of elevated concentrations have often fallen short of the 0.8 minimum ratio of $\mathrm{PM}_{2.5}$ to $\mathrm{PM}_{10}$ expected from the historical data. Three periods of low ratios have occurred directly after earthquakes with ground motions strong enough to trigger liquefaction, namely $22^{\text {nd }}$ February $2011,13^{\text {th }}$ June, 2011 and $23^{\text {rd }}$ December 2011. A fourth period occurred when Christchurch experienced two episodes of snowfall and gritting took place - a rare event in Christchurch. Fig. (5) shows the much more variable relationship between the measured $\mathrm{PM}_{10}$ and $\mathrm{PM}_{2.5}$ during 2011 in comparison with the historical relationship. 


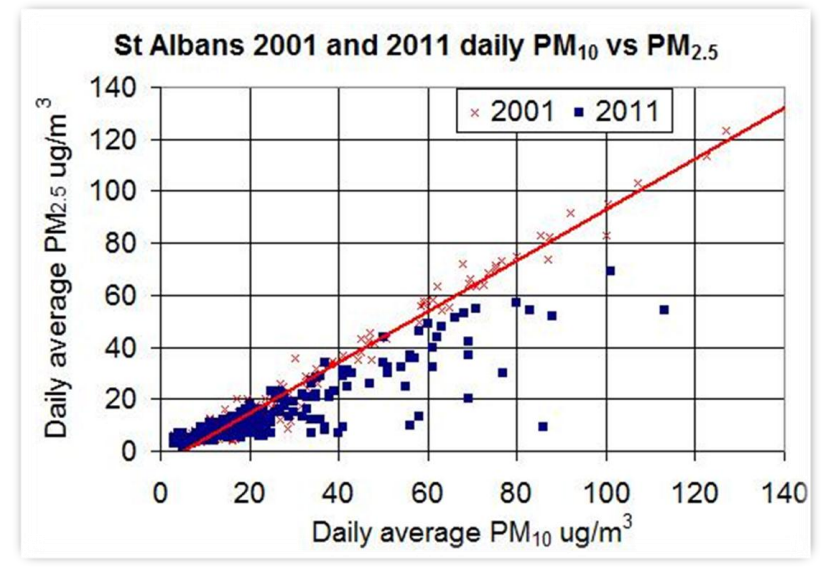

Fig. (5). $\mathrm{PM}_{2.5}$ and $\mathrm{PM}_{10}$ data measured at St. Albans monitoring site during seismically active 2011 , indicating a much larger coarser fraction during periods of elevated concentrations [13].

\section{Other New Potential Sources of Particulate Matter}

The fact that certain periods of elevated concentrations of coarse fraction $\mathrm{PM}_{10}$ are the direct result of airborne liquefaction dust is supported by the timing of the days with elevated concentrations in relation to the major quakes and aftershocks experienced by the city. For instance, in the two weeks after the February 22 quake there were strong winds that would have contributed to the drying and re-entrainment of liquefaction dust, which led to elevated concentrations of coarse fraction $\mathrm{PM}_{10}$, as shown by the black data points in Fig. (6). However, other periods, such as after the June 13 quake when wintertime wood-burning was occurring and wind speeds were lower, are more ambiguous. Liquefaction silt dust cannot be confidently distinguished from combustion particles or the dust from grit applied to roads during the snow storms.

The earthquakes have caused substantial dust from destruction of buildings and roads, and the on-going work to repair or make safe the city's buildings and infrastructure is a continual, un-quantified new source. In addition to new sources of coarse material, shifts in fuel consumption and domestic heating requirements mean the level of fine fraction PM may not have remained stable either. The Ministry for Economic Development [14] reports that during 2011, demand for petrol decreased by $6 \%$ in Canterbury, while demand for diesel increased by $5 \%$. This is presumably due in part to the extra heavy machinery in operation in the city, while Stewart [15] reports that an extra 1500 truck movements per day were expected through to at least June 2012 in order to clear demolition debris from the city.

Environment Canterbury has, since 1991, introduced a series of measures to restrict the installation and use of open fires and wood burners that are not accredited to a low emission standard, as part of its air quality management strategy. The restrictions on operating unauthorized burners and open fires were not enforced during the winter of 2011 and 2012 in order that residents could heat their homes however were possible. It is estimated that over 60000 residences are in need of repair [16] and much of the damage will compromise the ability of a house to retain heat, exclude draughts and maintain a warm, healthy internal environment.

Although many may begin to burn wood for domestic heating, others will be unable to because of this damage. By May 2012, 3000 claims for damaged open fires had been made [17]. It is not possible to establish whether there has been a net gain or loss of wood burner emissions over the winter period and if there was a gain, how much of that was due to the unusually cold winter creating more heating demand compared with changes brought about by the earthquakes.

Therefore, as a consequence of the 2010 and 2011 earthquakes, people in Christchurch were exposed to new sources of $\mathrm{PM}_{10}$ material from liquefaction silt and building collapse and demolition, and there were increased

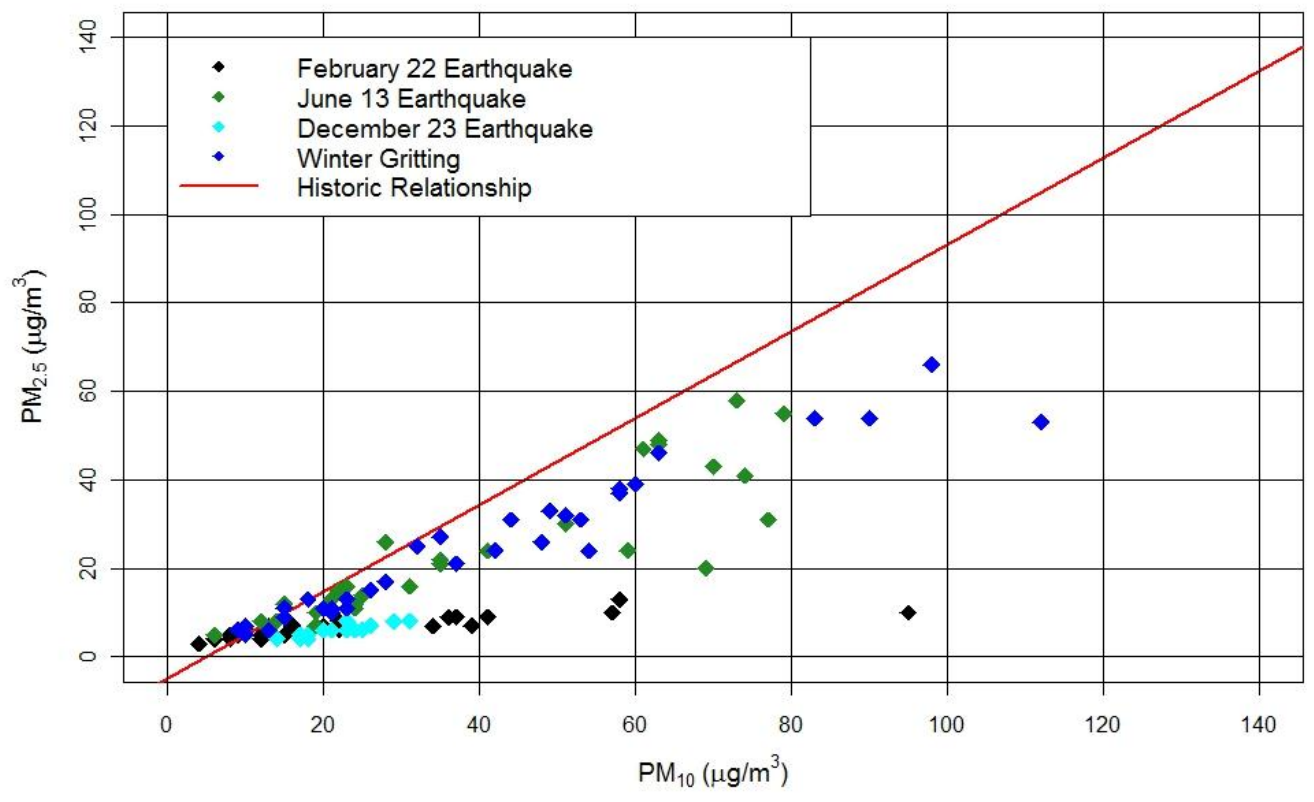

Fig. (6). Data points associated with particular PM inducing events. 
concentrations in Christchurch's usual $\mathrm{PM}_{10}$ sources from domestic fires (wood and coal) and diesel-powered vehicle emissions. The exposure to some of these air contaminants will continue as the city repairs and rebuilds.

\section{Potential Health Effects}

The World Health Organization [18] recommends an annual mean concentration of $\mathrm{PM}_{10}$ of less than $20 \mu \mathrm{g} \mathrm{m}^{-3}$ to guard against health effects. Christchurch's 2011 annual mean concentration was above this level for the first time since 2006, and rose against a steadily decreasing trend. Fig. (7) shows the decreasing trend in maximum hourly values of $\mathrm{PM}_{10}$ since 2001, and how the 2011 values for $\mathrm{PM}_{10}$ and $\mathrm{PM}_{2.5}$ compare. It suggests that the 2011 increase was entirely due to increased coarse fraction PM, as the $\mathrm{PM}_{2.5}$ value is in line with the trend. Measurements for 2012 to date, which include the winter period, show that the decreasing trend has resumed and that 2011 was anomalous.

The specific effects of breathing in liquefaction dust will be directly linked to the size of particles inhaled and their chemical nature. A recent report into the composition of the liquefacted silt raises health concerns. Environmental Science and Research [19] reports that the silica content of Christchurch's liquefaction silt could be as high as $66 \%$, and note that freshly exposed silica can have sharper edges that can penetrate the lungs and can be potentially more harmful than weathered silica particles. Although much of the liquefaction silt is larger than $\mathrm{PM}_{10}$, it may be broken up into smaller particles by being crushed under vehicle wheels and thus, new dust might enter into the $\mathrm{PM}_{10}$ size fraction without fresh liquefaction taking place.

Exposure to liquefaction silt dust was not uniform throughout the city. The eastern suburbs were more prone to liquefaction, with some areas being officially 'red zoned' and abandoned as future residential areas because of the substantial land damage. The most deprived areas of the city are also in the east of the city, meaning those being more vulnerable to the effects of poor air quality were most exposed to this source of air contamination.

It should be noted that the shift in fuel consumption also has health implications. The extra diesel consumption may be long-term, as reconstruction will continue for many years. Diesel emissions are acknowledged carcinogens [20] as well as contributing to the amount of finer fraction particulate matter in the atmosphere, so this adds to the potential health burden of the exposed populace.
These health effects will be challenging to distinguish from the extra burdens brought on from living through sudden traumatic and on-going stressful events and dwelling within compromised homes.

\section{FUTURE AIR QUALITY IN CHRISTCHURCH}

\section{Discussion}

It is clear from the increased periods of elevated concentrations due to the coarser $\mathrm{PM}_{10}$ fraction, that a new source or sources of particulate matter have been introduced into the city of Christchurch. What is unclear, at this stage is, how great a source liquefacted silt is in itself, compared to the increased levels of dust due to the demolition of buildings and road reconstruction that have also been a result of the on-going earthquakes. Observations of this initial period were compounded by 2011 being an unusually cold winter, requiring gritting to take place and thus releasing another source of crustal material into the city.

The downward trend in $\mathrm{PM}_{10}$ levels of previous years seems to have resumed after the initial upset of 2011. The 2012 data suggest that liquefaction silt dust is no longer a major contributor to Christchurch's $\mathrm{PM}_{10}$ load (the $\mathrm{PM}_{2.5}$ and $\mathrm{PM}_{10}$ fractions are almost equal, consistent with historical data), and that most of the building demolition dust is being managed (damped by water) or even if greater than $\mathrm{PM}_{10}$ and therefore, while likely to have nuisance effects for some individuals, is unlikely to represent a public health risk. Factors working in favour of lower future concentrations are the number of chimneys that have been destroyed through the earthquakes and the opportunity to replace damaged chimneys and wood burners with cleaner types of domestic heat, such as heat pumps.

The implications of a step change in regular emissions from domestic wood-burning must also be considered. It is estimated that at least 10000 residences will need to be abandoned [15] as well as the 60000 requiring repair. Replacement of so many damaged burners or chimneys with clean heat alternatives could see a marked improvement in normal wintertime air quality in Christchurch. However, the city's infra-structure is precarious and residents may be resistant to changing to heating sources that are vulnerable to power outages. In light of that, there may be a swing towards domestic burning as a more reliable heating source. Woodburners may remain an important primary or secondary domestic heating method for many.

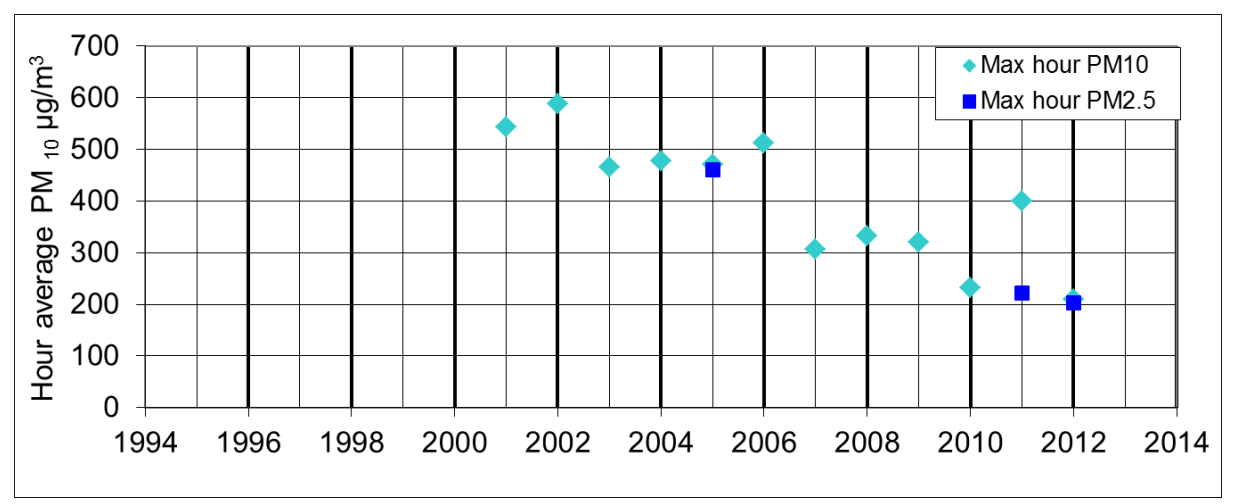

Fig. (7). Decreasing trend in maximum hourly $\mathrm{PM}_{10}$ concentrations compared $\mathrm{PM}_{2.5}$ concentrations in 2011 and 2012. 


\section{Future Research}

Environment Canterbury continues to measure $\mathrm{PM}_{2.5}$ at its St. Albans site, in order to monitor the concentrations of fine and coarse fractions. The health effects, if any, of the liquefaction silt dust exposures will take time to manifest, and it will be some time before the effects of the air quality during the earthquake period can be distinguished from other health impacts, such as the stress of the initial disaster and on-going stress of living with aftershocks, and the greater proportion of the populace living in compromised buildings that are colder as a result. In addition the population in question will not be static. There has been a net migration away from Christchurch since February 2011, but with the rebuild beginning, the city's population will increase to meet the demand for labour. Despite the methodological and statistical challenges of analysing such factors, it is worthwhile.

The upheaval in Christchurch will continue for many years to come, not just through continued, but (it is hoped) less frequent seismic activity, but through the massive reconstruction effort required to rebuild the city's centre and infrastructure. This presents an important opportunity to observe the effects of a natural disaster on a city and in the future, how a substantial rebuild of a central business district can change the air quality of a city through different land use and traffic patterns. This could provide valuable insights for other urban areas responding to seismic events or other natural disasters throughout the world.

\section{CONFLICT OF INTEREST}

The author confirms that this article content has no conflict of interest.

\section{ACKNOWLEDGEMENTS}

Thanks are paid to Wendy Williamson of ESR and Tim Mallett of Environment Canterbury for comments and suggestions.

\section{REFERENCES}

[1] Villemure M, Wilson TM, Bristow D, Gallagher M, Giovinazzi S, Brown C. Liquefaction ejecta clean-up in Christchurch during the 2010-2011 earthquake sequence. Conference proceedings 2012 New Zealand. Soc Earthquake Engineer Ann Conf 2012.
[2] Canterbury Earthquake Recovery Authority (CERA), Tonkin \& Taylor land damage presentation CCC area 23 June 2011. http://cera.govt.nz/land-information/land-damage\#overview Accessed 25/07/2012.

[3] Efstathioua MN. A case study of the association of total ozone variability with major earthquakes in Greece during 2001-2010. Remote Sens Lett 2012; 3(3): 181-90.

[4] Hsu SC, Huang YT, Huang Jr C, et al. Evaluating real-time airquality data as earthquake indicator. Sci Total Environ 2010; 408: 2299-304.

[5] Okada Y, Mukai S, Singh RP. Changes in atmospheric aerosol parameters after Gujarat earthquake of January 26, 2001. Adv Space Res 2004; 33: 254-8.

[6] Lekkas EL. The role of earthquake-related effects in urban complexes. Natural Hazards 2002; 25: 23-35.

[7] Adelier K, Aydingun O. Liquefaction during the June 27, 1998 Adana-Ceyhan (Turkey) Earthquake. Geotech Geologic Engineer 2000;18: 155-74.

[8] Kossman M, Sturman A. The surface wind field during winter smog nightsin Christchurch and coastal Canterbury, New Zealand. Int J Climatol 2004; 24: 93-108.

[9] Environment Canterbury (ECan), Invenory of emissions to air in Christchurch, 2009. Report no. R11/17. Environ Canterb 2009.

[10] Allen GA, Miller PJ, Rector LJ, Brauer M, Su JG. Characterization of valley winter wood smoke concentrations in northern NY using highly time-resolved measurements. Aero Air Quality Res 2011;11: 519-30.

[11] Wang Y, Hopke PK, Utell MJ. Urban-scale Spatial-temporal variability of black carbon and winter residential wood combustion particles. Aeros Air Qual Res 2011; 11: 473-81.

[12] McKendry IG, Sturman AP, Vergeiner J. Vertical profiles of particulate matter size distributions during winter domestic burning in Christchurch, New Zealand. Atmosph Environ 2004; 38: 4805-13.

[13] Environment Canterbury (ECan), Why is the number of high pollution days in Christchurch higher in 2011 compared to recent years? Report no. E11/37. Environ Canterb 2011.

[14] Ministry for Economic Development, New Zealand Energy Data File. ISSN 2011; 1177-6684 (Online version).

[15] Stewart P. Home demolition and recycling. Build 2011;126: Oct/Nov 2011.

[16] MacKenzie A. Christchurch rebuild. Build 2011;126.

[17] Mallett T. Is Christchurch likely to meet the NESAQ targets for PM10? Report no R12/40. Environ Canter 2012.

[18] World Health Organisation (WHO) Air quality guidelines for particulate matter, ozone, nitrogen dioxide and sulfur dioxide: Global update 2005, 2006.

[19] Environmental Science and Research (ESR), $\mathrm{PM}_{10}$ and Christchurch liquefaction silt. Report no. FW11083. 2012.

[20] International Agency for Reasearch on Cancer (IARC), IARC: Diesel engine exhaust carcinogenic, Press Release No. 213, WHO 2012. 